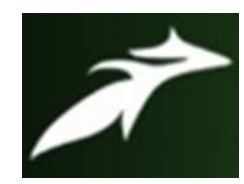

Kumari Shipra, International Journal of Advances in Agricultural Science and Technology,

Vol.1 Issue. 1, December- 2013, pg. 117-124

ISSN: 2348-1358

\title{
Impact Assessment on Rural Women through Mushroom Cultivation Training Programme
}

\author{
Mrs. Kumari Shipra \\ Assistant Professor, Dept. of Home Science Extension Education, RAU, Pusa, Samastipur Bihar \\ DOI: 10.47856/ijaast.2013.v01i1.001
}

\begin{abstract}
INTRODUCTION
Rural women play a vital role in farm and home system. She contributes substantially in the physical aspect of farming, livestock management, post-harvest and allied activities. Women contribute $50-60 \%$ of labour in farm production in India. There is evidence to suggest that if agriculture were focused on women, outputs could increase by as much as $10-20 \%$, the ecological balance could be restored, and food security of communities improved.
\end{abstract}

Mushroom growing is one of the agricultural activities in which women can play a vital role without sacrificing their household responsibilities. Mushroom cultivation is simple, low cost and suitable for rural areas, is labour intensive and can provide employment in both the semi-urban and rural areas. Mushroom cultivation is an important subsidiary occupation for the landless and small farmers and can be adopted by them in leisure time. Mushroom being an indoor activities and can be cultivated by utilise vertical space giving high productivity per unit area and time. Mushroom cultivation is a low cost enterprise. With the changing life style food habits increased awareness in urban and semi urban are about health benefits of mushroom and increasing population.

The mushroom consumption is increasing faster rate. It is an economical crop to cultivate, requiring low resources and area, can be grown throughout the world and all over the year from low-cost materials. There is tremendous potential and appeal for growing a highly nutritious food with excellent taste from substrates that are plentiful and not very expensive (Beetz and Kustudia, 2004). Also, it is very environmental friendly, capable of converting the lingo cellulosic waste materials into food, feed and fertilizers (Hadar et al., 1992; Arafat, 2010).Promotion of mushroom cultivation could relieve pressure on land, increase food and nutritional security and uplift the status of women through earning additional income and in household decision making as far as concerned (Manju et al., 2012) [3] .Keeping in view the above facts the present study was conducted to find out the impact of mushroom cultivation on rural women through training programme in Samastipur district if Bihar. 


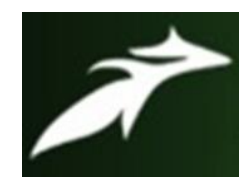

Kumari Shipra, International Journal of Advances in Agricultural Science and Technology,

Vol.1 Issue. 1, December- 2013, pg. 117-124

ISSN: 2348-1358

\section{METHODOLOGY}

The study was conducted in Samastipur district of Bihar. There are 38 districts in state and the dissemination of mushroom technology is fast in all districts of state. Out of 38 districts, Samastipur district was selected purposively for the study because of the fact that RPCAU is located in same district and there is a training centre at RPCAU. All together there are 20 blocks in Samastipur. Out of which Pusa and Kalyanpur blocks have been selected for study purpose based on assumption that these blocks have the largest number of trained beneficiaries. Out of these only three villages were selected two from Pusa namely Birauli and Deopar and one from Kalyanpur namely Ladhaura. A complete list of the beneficiaries who have undergone through training on mushroom cultivation from RPCAU, Pusa was obtained from training centre. 25 beneficiaries respondents from each of three villages where purposely selected. Hence all total 75 respondents were selected, through random sampling. The data were collected by using pre structural interview schedule and were subjected to statistical analysis.

\section{RESULT AND DISCUSSION}

Knowledge of Respondents about mushroom cultivation through training programme

The frequency distribution of respondents at two point per and post knowledge about training program through scientific mushroom cultivation technology has been presented in table:-1

\section{TABLE 1}

Distribution of respondents by pre -post training knowledge score

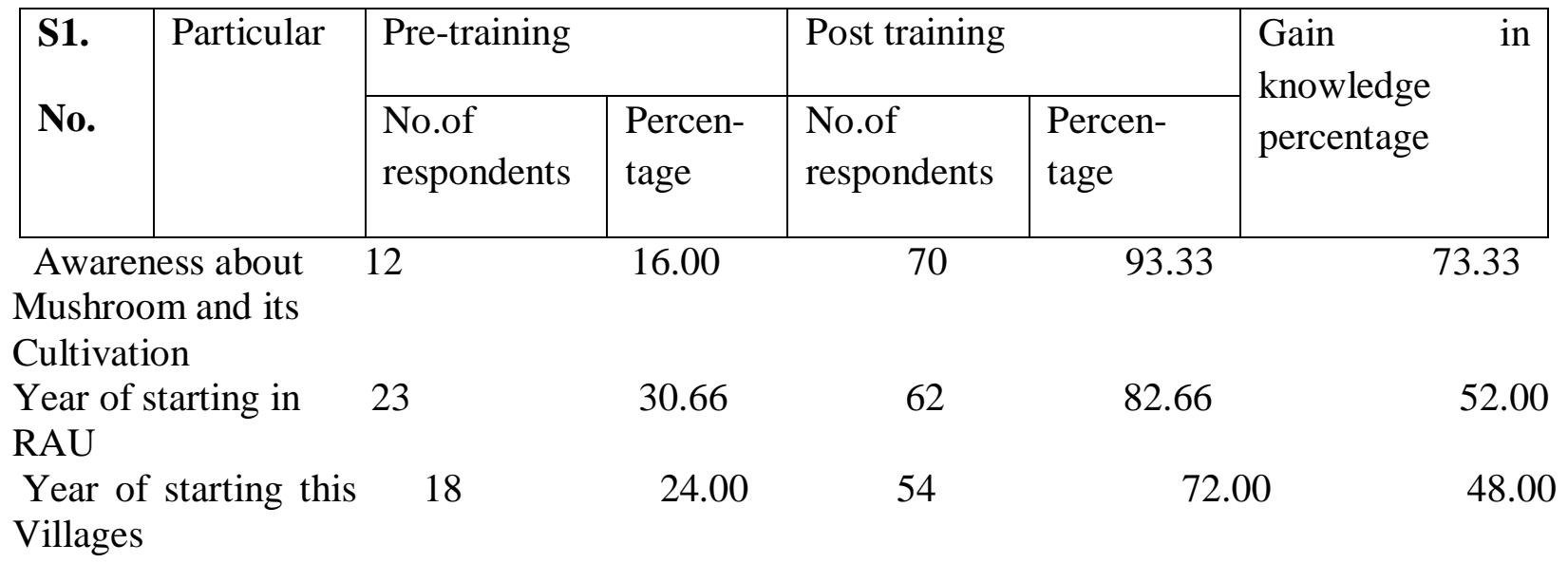




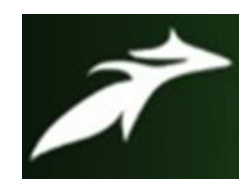

Kumari Shipra, International Journal of Advances in Agricultural Science and Technology, Vol.1 Issue. 1, December- 2013, pg. 117-124

ISSN: 2348-1358

Some ideas about mush- 27

36.00

67

89.00

53.33

room and its cultivation

Duration of training

Its evident from table that post training knowledge score of respondents about training program related to mushroom cultivation was very high in comparison to pre-training knowledge score The information gathered through collected data showed that maximum gain in knowledge was reflected at the awareness about mushroom and its cultivation was $73.33 \%$. This may be due to the fact that awareness about mushroom and its cultivation is first step to cultivate mushroom. It is very simple skill, easy to understand and involve less cost to acquire information from RAU Scientists.Therefore these training has been adopted by the majority of trainees for one week training program whereas $48 \%$ respondents were well know about the year of starting in this village. This may be due to ignorance and lack of interest among the respondents.

To assess the impact of mushroom cultivation training program the knowledge of the respondents was measured with the help of Standardized i.e. pre-training and post training .On the basis of score respondents was classified into three categories i.e. low (0-11), medium (1222) level of knowledge presented in a table 2.

Table 2

\section{Pre-training knowledge score of respondents}

\begin{tabular}{lcc|c|}
\hline Knowledge level & No. of respondents & Percentage & Mean \\
\hline Low (0 to 11$)$ & 37 & 49.34 & 9.5 \\
Medium(12 to 22) & 32 & 42.66 & 8.00 \\
High(23 to 33) & 06 & 100.00 & \\
\hline \multicolumn{1}{c}{ Total } & 75 & \multicolumn{2}{c}{100} \\
\hline
\end{tabular}




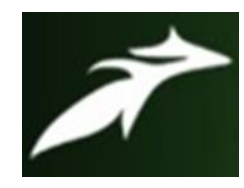

Kumari Shipra, International Journal of Advances in Agricultural Science and Technology,

Vol.1 Issue. 1, December- 2013, pg. 117-124

ISSN: 2348-1358

Table revealed that the majority $49.34 \%$ of the respondents has low level of knowledge about mushroom cultivation followed by medium level i.e. $42.66 \%$ while the minimum \% i.e. $8 \%$ of women had high level of knowledge .Mean score related to mushroom cultivation before imparting training was found to be 9.5

Table 3

Post training knowledge score of respondents

\begin{tabular}{lcc|c|}
\hline Knowledge level & No. of respondents & Percentage & Mean \\
\hline Low (0 to 11) & 12 & 16.00 & 20.24 \\
Medium(12 to 22) & 40 & 53.33 & 30.67 \\
High(23 to 33) & 23 & 100.00 & \\
\hline \multicolumn{2}{c}{ Total } & 75 &
\end{tabular}

It is clear from table that after exposure of training the majority of respondents $53.33 \%$ has medium level of knowledge score followed by $30.60 \%$ had high level of knowledge score $16.00 \%$ of respondents showed low level of knowledge score related to mushroom cultivation. This table also indicates that mean knowledge score of respondents after getting the training increase up to 20.24 .

Table 4

\section{Village wise level of knowledge}

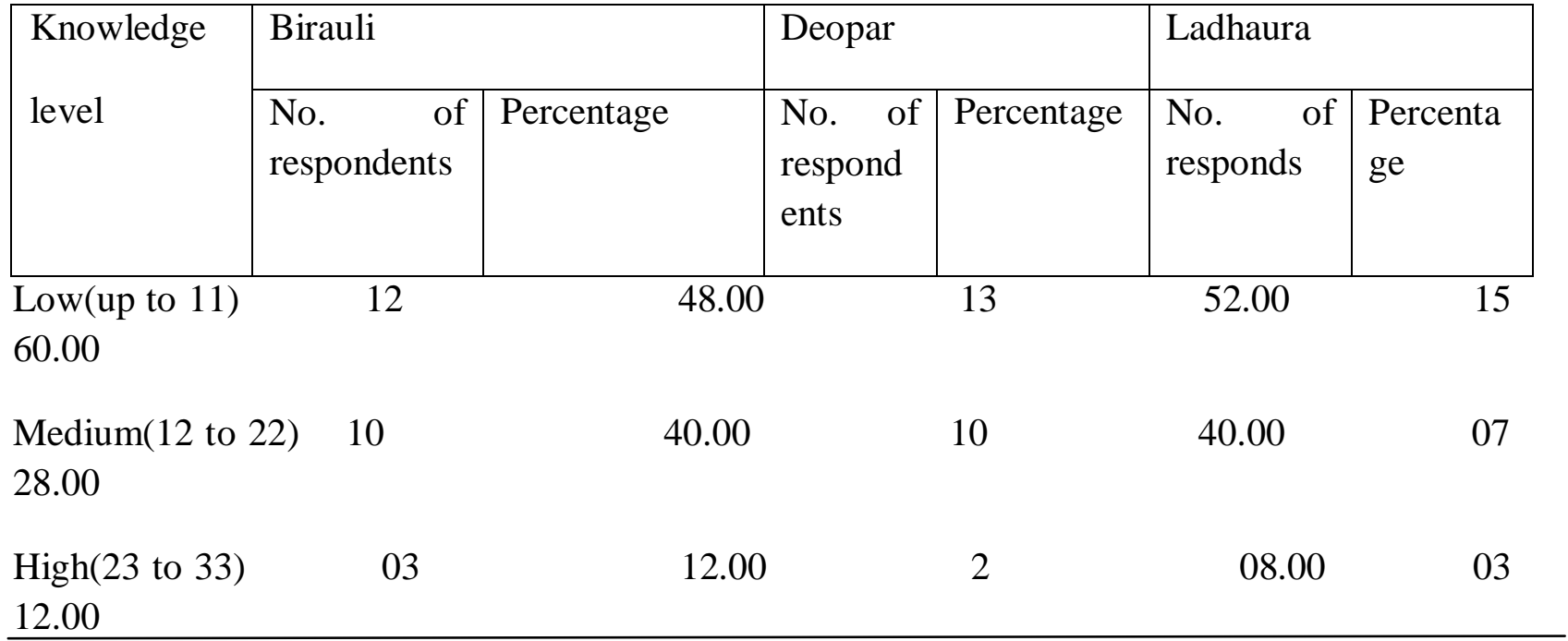




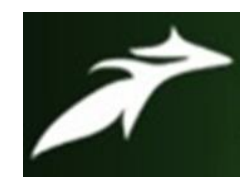

Kumari Shipra, International Journal of Advances in Agricultural Science and Technology, Vol.1 Issue. 1, December- 2013, pg. 117-124

ISSN: 2348-1358

Total 25

100.00

25

100.00

100.00

It is clear from above table that in Birauli $48 \%$ of the respondents has low level of knowledge followed by $40 \%$ had medium level of knowledge while only $12 \%$ had high level knowledge about mushroom cultivation.

In Deopar 52 percent of respondents had low level of knowledge followed by 40 percent had medium level for knowledge only 8 percent had high level of knowledge.

In Ladhaura 60 percent of respondents had low level of knowledge followed by 28 percent had medium level of knowledge only 12 percent of respondents had high level of knowledge related to mushroom cultivation.

\section{Gain in Knowledge:-}

Gain in knowledge in one of the important indicators to measure the impact of any training .The respondents were educated in mushroom cultivation technologies through selected indicators instrument and their combination .After training the level of knowledge of respondents was measured with the help of same knowledge test which was administrated before impact training to them. The gain in knowledge was measured by subtracting the pre-training knowledge score obtained after training i.e. post-training knowledge scores. The number of respondents by gain in knowledge score in presented in table.

\section{Table 5}

\section{Knowledge gain by respondents after training}

\begin{tabular}{lcc|c|}
\hline Knowledge level & No. of respondents & Percentage & Mean \\
\hline Low(0 to 10) & 38 & 50.66 & 10.75 \\
Medium(11 to 22) & 34 & 45.34 & \\
High(23 to 33) & 03 & 4.00 & \\
\hline Total & 75 & 100 & \\
\hline
\end{tabular}

It can be seen from above table that out of 75 respondents $50.66 \%$ were having low level knowledge followed by $45.34 \%$ medium level of knowledge while only $4.00 \%$ of respondents 


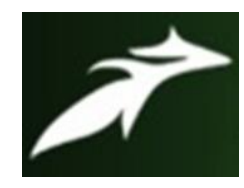

Kumari Shipra, International Journal of Advances in Agricultural Science and Technology,

Vol.1 Issue. 1, December- 2013, pg. 117-124

ISSN: 2348-1358

gained high level of knowledge related to mushroom cultivation and their mean score was found to 10.75 .

\section{Impact of training programme on economical status of respondents income level}

In the present study the impact of mushroom cultivation training programme on economical status of rural women and their income has been derived from different sources namely. Poultry/birds, pigs, cow, buffaloes, agriculture and mushroom production. Mushroom income was calculated on the basis of harvest price whereas income from different source of rural women through various training like mushroom cultivation, bee-keeping and through different production system. Hence it is a mandatory to assess the income level of rural women about pretraining and post training. For the purpose income from different source and mushroom cultivation was quantified and average income for different categories was calculated in before training and after training. Thus farm size-wise average income being presented in Table 4.

Table 6

Average income level of respondents per annum from different source included Mushroom Cultivation.

\begin{tabular}{l|l|l|l|l|}
\hline Categories & $\begin{array}{l}\text { No. of } \\
\text { respondents }\end{array}$ & $\begin{array}{l}\text { Income in } \\
\text { rupees } \\
\text { training }\end{array}$ & $\begin{array}{r}\text { Income in } \\
\text { before } \\
\text { rupees } \\
\text { training }\end{array}$ & Difference \\
after & 13812.5 & 2937.5 \\
\hline $\begin{array}{l}\text { Below poverty line (up to } \\
\text { 12000) }\end{array}$ & 32 & 22454.54 & 26709.09 & 4254.55 \\
Low (12000-25000) & 22 & 27933.33 & 30940.00 & 3006.67 \\
Medium (25000-50000) & 15 & 52333.33 & 54366.66 & 2033.33 \\
High (50000 \& above) & 06 & & & \\
\hline Total & $\mathbf{7 5}$ & $\mathbf{1 1 3 5 9 6 . 2 2}$ & $\mathbf{1 2 5 8 2 8 . 2 5}$ & $\mathbf{1 2 2 3 2 . 0 5}$ \\
\hline
\end{tabular}

This table indicated that respondents involved in mushroom cultivation training Programme has belonged to low income groups and their average income from different source was i.e. $22,454.54 \mathrm{Rs} /$ annum before training and after growing mushroom their income level increased up to $26,709.09$ followed by medium income group of respondents i.e 27,933.33 Rs /annum before training and after getting training their income level increase up to 30,940 Rs/annum. This table also indicated that even below poverty line women involved in mushroom cultivation 


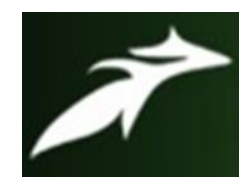

Kumari Shipra, International Journal of Advances in Agricultural Science and Technology,

Vol.1 Issue. 1, December- 2013, pg. 117-124

ISSN: 2348-1358

training had their income level increase from 10.75.00 Rs/annum to 13.812.5 Rs/annum. In case of high income group their production after getting training it increase from 52,333.33 Rs/annum to $54,366.66 \mathrm{Rs} /$ annum so it may be attributed that low income group had involved in mushroom cultivation more efficiency then other income group because its cultivation require no more space. Less expensive and even technology is very simple that's why even landless women or low income group of respondents prefer to do it with more interest and enthusing.

\section{Table 7}

\section{Problems faced by respondents during the mushroom cultivation}

After collecting the data it was found that the beneficiaries of this training programme had to face a lot of problems in its production which has been depicted through Table 7

\section{Distribution of respondents problem faced during the mushroom cultivation}

\begin{tabular}{|c|l|c|c|c|}
\hline Si.No & \multicolumn{1}{|c|}{ Particulars } & No. of respondent & Percentage & Rank \\
\hline 1. & Lack of resource available & 28 & 37.33 & III \\
2. & Lack of money & 35 & 46.66 & II \\
3. & Non availability of market & 47 & 62.66 & I \\
4. & Lack of time and energy & 25 & 33.33 & IV \\
5. & Lack of technical advice & 23 & 30.66 & V \\
\hline
\end{tabular}

This table revealed that majority of respondents were non-availability of market to sell mushroom i.e. 62.33 percent followed by 46.66 per cent were lack of money. Around 37.33 per cent were lack of resource available, 33.33 per cent of respondents had lack of time and energy only 30.66 per cent were lack of technical advice. Hence it may be say that major problems arises during mushroom cultivation was due to marketing facilities among the respondents.

\section{CONCLUSION}

The investigator attempted to study the impact of mushroom cultivation on rural women through training programme increase their knowledge and change their attitude after providing training Mushroom cultivation can generate self-employment and its cultivation is less expensive and technology is simple that's women can do it. The study revealed that exposure of training had increased the knowledge of rural women regarding all sub-components of mushroom cultivation. The study further inter-related that respondents after exposure training acquired knowledge and change their attitude to the extent which was increased only moderate level. 


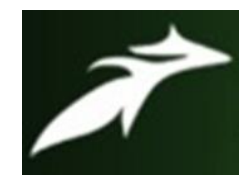

Kumari Shipra, International Journal of Advances in Agricultural Science and Technology,

Vol.1 Issue. 1, December- 2013, pg. 117-124

ISSN: 2348-1358

\section{REFERENCES}

[1]. Shoal and Fulzela (1986) while assessing the impact of training programme of K.V.K and N.D.R.I karnal found that the training programme was very effective to the extent of improving the knowledge of trainees as well as retaining the gained knowledge to a considerable level.

[2]. Verma et al. (1993) in his study found that rural women had gained sufficient level of knowledge after training exposure in different improved home practices.

[3]. Anil et al. (1994) found that 29.30 percent increase in knowledge on improved farm technology due to training.

[4]. Thorat and Joshi (1997) concluded that the percentage of high adopters is more in case of trained rural women belonged to aged group of 26 to 40 years.

[5]. Singh and Prasad (1998) reported that there was a considerable increase in knowledge of farmers after training. It was found to be maximum in simple items and minimum in different items.

[6]. Sanyogita (2000) found that a training on oyster mushroom cultivation was formulated for unemployed youth and homemakers following the system approach to training in India. The impact of training was quantified by reaction, learning and performance evaluation of training. 